\title{
Differential inhibition in the human vas deferens by phenoxybenzamine: a possible mechanism for its contraceptive action
}

\author{
N. I. B. Amobi and I. C. H. Smith* \\ Biomedical Sciences Division, King's College, Campden Hill Road, London W8 7AH, UK
}

\begin{abstract}
The effect of phenoxybenzamine on in vitro contractile responses of human vasectomy tissues was investigated. Phenoxybenzamine $\left(0.01-10 \mu \mathrm{mol} \mathrm{l}^{-1}\right)$ produced a differential inhibition of contractions induced by noradrenaline $\left(1-300 \mu \mathrm{mol} \mathrm{I}{ }^{-1}\right)$ in the human vas deferens in that it blocked the longitudinal but not the circular muscle. Contractions of both muscle types induced by noradrenaline $\left(100 \mu \mathrm{mol} \mathrm{l}^{-1}\right)$ were inhibited by either prazosin (0.01-10 $\mu \mathrm{mol} \mathrm{l}^{-1}$ ), a competitive $\alpha_{1}$-selective adrenoceptor antagonist or benextramine $\left(0.01-10 \mu \mathrm{mol} 1^{-1}\right)$, an irreversible $\alpha_{1}$-adrenoceptor blocker, but were unaffected by chloroethylclonidine $\left(0.1-100 \mu \mathrm{mol} \mathrm{l^{-1 }}\right)$, an irreversible $\alpha_{1 \mathrm{~B}}$-adrenoceptor blocker. In calcium-free/EGTA ( $1 \mathrm{mmol} \mathrm{l}^{-1}$ ) medium, contractions of the longitudinal but not circular muscle induced by noradrenaline $\left(100 \mu \mathrm{mol} \mathrm{l}^{-1}\right)$ were inhibited by phenoxybenzamine $\left(0.01-1 \mu \mathrm{mol} \mathrm{l}^{-1}\right)$. Chloroethylclonidine $\left(10-100 \mu \mathrm{mol} \mathrm{l}^{-1}\right)$ was ineffective on both muscle types in calcium-free medium, but, on readmission of calcium, it markedly inhibited the recovery of longitudinal but not the circular muscle. These results suggest a mechanism for the male contraceptive action of phenoxybenzamine by a selective blockade of longitudinal but not circular muscle contractions. The results are discussed in relation to (i) the possible involvement of receptor reserves for noradrenaline and of $\alpha_{1}$-adrenoceptor subtypes coupled in the longitudinal and circular muscle to different mechanisms for increasing cytosolic calcium, (ii) a role in the longitudinal muscle for chloroethylclonidine-sensitive $\alpha_{1}$-adrenoceptors in replenishment of a functional pool of intracellular calcium and (iii) the inhibition of sperm emission by phenoxybenzamine.
\end{abstract}

\section{Introduction}

Phenoxybenzamine inhibits sperm emission in patients without affecting libido, penile erection, orgasm or frequency of coitus (Kedia and Persky, 1981). This effect is reversed on its withdrawal. Its use for the control of premature ejaculation and as a male contraceptive drug is also reported not to affect testicular function, hormonal balance or blood pressure (Homonnai et al., 1984). No evidence of retrograde ejaculation was found.

Phenoxybenzamine is an irreversible $\alpha$-adrenoceptor antagonist that is more potent at blocking $\alpha_{1}$ - than $\alpha_{2}$-adrenoceptors in in vivo and in vitro preparations (Hamilton et al., 1983; Minneman, 1983). Although its therapeutic action is due mainly to the blockade of $\alpha_{1}$-adrenoceptors, the clinical use of other traditional $\alpha_{1}$-adrenoceptor antagonists are rarely reported to inhibit sperm emission (Smith and Harclerode, 1985; van Zwieten, 1990; Brock and Lee, 1993). Thus, the mechanism underlying the contraceptive action of phenoxybenzamine remains unknown. Thioridazine, a neuroleptic drug with a different therapeutic profile from phenoxybenzamine is also noted for inhibition of sperm emission in patients (Greenberg and Carrillo, 1968; Kotin et al., 1976). An earlier

*Correspondence.

Received 15 June 1994. study (Amobi and Smith, 1992) reports that thioridazine inhibits the contractions induced by noradrenaline or potassium in the longitudinal but not the circular muscle of the human vas deferens. There are no comparable studies on the effects of phenoxybenzamine on the contractions of the human vas deferens.

The present work was undertaken to (i) investigate the effects of phenoxybenzamine on contractions induced by noradrenaline in the longitudinal and circular muscle of the human vas deferens and (ii) determine whether the responses are modified in a manner comparable to the effects reported for thioridazine. A preliminary report of some of these results has been communicated to the Physiological Society (Amobi and Smith, 1994a, b).

\section{Materials and Methods}

Tissue preparation and drugs

Epididymal specimens of human vas deferens $(5-10 \mathrm{~mm}$ long) were obtained after elective vasectomies of healthy, fertile men. The specimens were suspended horizontally (resting tension, $3-5 \mathrm{mN}$ ) in a jacketed Perspex chamber and superfused at $2.5 \mathrm{ml} \mathrm{min}{ }^{-1}$ with Krebs' saline $\left(35.8-36^{\circ} \mathrm{C}\right)$, 
gassed with $95 \% \mathrm{O}_{2}$ and $5 \% \mathrm{CO}_{2}$ as described by Amobi and Smith (1992). Mechanical responses were recorded via a force-displacement transducer (compliance $0.4 \mathrm{~mm} \mathrm{~g}^{-\mathrm{I}}$ ), coupled to a Venture Servoscribe potentiometric recorder. Drugs used were phenoxybenzamine hydrochloride (Smith, Kline and French, Welwyn Garden City), chloroethylclonidine (Research Biochemicals International, Natick, MA), prazosin hydrochloride (Pfizer Ltd, Sandwich), propranolol hydrochloride (ICI Pharmaceuticals, Macclesfield), L-noradrenaline acid tartrate (Winthrop, Guildford), oestradiol (BDH Chemicals, Poole), desipramine (Geigy Pharmaceuticals, Horsham) and from Sigma (Poole): benextramine, L-ascorbic acid and EGTA. The perfusates also contained ascorbic acid $\left(20 \mu \mathrm{mol} \mathrm{I}^{-1}\right)$ as an antioxidant; oestradiol ( $1 \mu \mathrm{mol} \mathrm{I}{ }^{-1}$ ) and desipramine $(0.1 \mu \mathrm{mol}$ $\left.\mathrm{l}^{-1}\right)$ as inhibitors of extraneuronal and neuronal noradrenaline uptake, respectively, and the $\beta$-adrenoceptor blocker, propranolol $\left(1 \mu \mathrm{mol} \mathrm{^{-1 }}\right)$. Calcium-free solution was prepared by isotonic replacement of $\mathrm{CaCl}_{2}$ with $\mathrm{NaCl}$ and the addition of EGTA ( $1 \mathrm{mmol} \mathrm{l}^{-1}$ ).

\section{Contractile responses of human vas deferens specimens}

Different vasectomy specimens exhibited different patterns of mechanical response (Amobi and Smith, 1992, 1993a). Of 190 specimens stimulated with noradrenaline $\left(100 \mu \mathrm{mol} \mathrm{l}^{-1}\right)$, 81 showed only increases in tension (i.e., shortening responses), 89 displayed decreases from and recovery to resting tension (i.e., lengthening responses) and 20 showed an initial increase in tension followed by a decrease below and recovery to resting tension. Responses from the right and left vas deferens of the same patient were not always similar. Previous histological studies have revealed a predominance of either longitudinal or circular muscle in specimens that displayed, respectively, shortening or lengthening. This finding, in conjunction with measurements of changes in luminal pressure, have identified the tissue shortening as being due to contraction of the longitudinal muscle and the tissue lengthening as resulting from the active contraction of the circular muscle (Anton and McGrath, 1977; Smith and Bray, 1990; Amobi and Smith, 1993b, 1995). The quantitative measurements described in the present study were from specimens that displayed either only shortening (i.e., contractions of the longitudinal muscle) or only lengthening (i.e., circular muscle responses). However, even with these, there is presumably some degree of mixing of the muscle types (Amobi and Smith, 1992).

\section{Experimental procedures and analysis}

Dose-response curves to noradrenaline were obtained using a progressive but non-cumulative dose sequence with exposures of 5-7 min at intervals of 10-12 min. The contractile response of either the longitudinal or circular muscle was measured as the maximum sustained change from passive resting tension (i.e., tonic responses) in the presence of noradrenaline. Rhythmic activity was excluded. A sigmoid curve fitting computer program was used to analyse the doseresponse curves and to determine the concentrations of noradrenaline producing $50 \%$ of the maximum response $\left(\mathrm{EC}_{50}\right)$ before exposure to phenoxybenzamine. Results are given as means \pm SEM and $n$ refers to the number of preparations. Only one preparation was obtained from each specimen. Statistical analysis was carried out using Student's $t$ test and, where appropriate, a one-way analysis of variance (ANOVA). A significant $F$ value from ANOVA tests with $P<0.05$ was followed by comparison of means using Tukey's honestly significant difference. Differences between the mean of control and experimental groups were considered significant at $P<0.05\left(^{*}\right)$ and highly significant at $P<0.01\left(^{* *}\right)$.

\section{Results}

\section{Effects of phenoxybenzamine}

In drug-free medium, the longitudinal and circular muscle showed a comparable sensitivity to noradrenaline with $\mathrm{EC}_{50}$ values of $20.6 \pm 5.3 \mu \mathrm{mol} 1^{-1}(n=6)$ and $22.6 \pm 8.7 \mu \mathrm{mol} 1^{-1}$ $(n=5)$. However, phenoxybenzamine produced different patterns of inhibition in the muscle types (Fig. I). In the longitudinal muscle (Fig. 1a), phenoxybenzamine $\left(0.1 \mu \mathrm{mol} \mathrm{l}^{-1}\right.$ applied for 15 or $25 \mathrm{~min}$ or $1.0 \mu \mathrm{mol} \mathrm{l}^{-1}$ for $15 \mathrm{~min}$ ) inhibited the contractions and progressively reduced the maximum response. In contrast, contractions of the circular muscle were much less susceptible to phenoxybenzamine (Fig. Ib). Phenoxybenzamine $\left(0.1\right.$ or $1.0 \mu \mathrm{mol} 1^{-1}$ applied for $\left.15 \mathrm{~min}\right)$ inhibited contractions induced by low doses of noradrenaline $\left(<10 \mu \mathrm{mol} \mathrm{l}^{-1}\right)$ without affecting the maximum response. An increase in the duration of exposure $\left(0.1 \mu \mathrm{mol} 1^{-1}\right.$ applied for $25 \mathrm{~min}$ ) slightly $(P>0.2)$ depressed (by 19\%) the maximum response.

Similar results were observed when the antagonist was applied simultaneously in the bath and through the lumen of the tissues to enhance access of the drug. Phenoxybenzamine $\left(0.1 \mu \mathrm{mol} \mathrm{^{-1 }}\right.$ applied for $\left.15 \mathrm{~min}\right)$ reduced the maximum contraction of only the longitudinal (by $54.5 \pm 6.6 \% ; n=4$ ) but not the circular muscle $(n=6)$. A tenfold increase in the concentration of phenoxybenzamine $\left(1.0 \mu \mathrm{mol} \mathrm{^{-1 }}\right)$ depressed the maximum contraction of the longitudinal muscle by $67 \pm 9.7 \%(n=4)$ and the circular muscle by $28.1 \pm 7.1 \%$ $(n=6)$.

\section{Effects of prolonged exposure to phenoxybenzamine, benextramine or prazosin}

Contractions of the longitudinal and circular muscle to maximal effective concentrations of noradrenaline $(100 \mu \mathrm{mol}$ $\left.1^{-1}\right)$ were studied after prolonged (35-40 min) superfusion with phenoxybenzamine; benextramine, an irreversible $\alpha_{1}$-adrenoceptor antagonist with a different mechanism of action (Benfy, 1982), or prazosin, a competitive $\alpha_{1}$-adrenoceptor antagonist.

Benextramine $\left(0.01-10 \mu \mathrm{mol} \mathrm{l^{-1 } )}\right.$ or prazosin (0.01$10 \mu \mathrm{mol} \mathrm{I}^{-1}$ ) inhibited contractions of both longitudinal and circular muscle (Fig. 2). In contrast, phenoxybenzamine inhibited contractions of only the longitudinal (Fig. 2a) but not the circular muscle (Fig. 2b) except at $10 \mu \mathrm{mol} \mathrm{l}^{-1}$. A similar effect was observed when graded concentrations of 

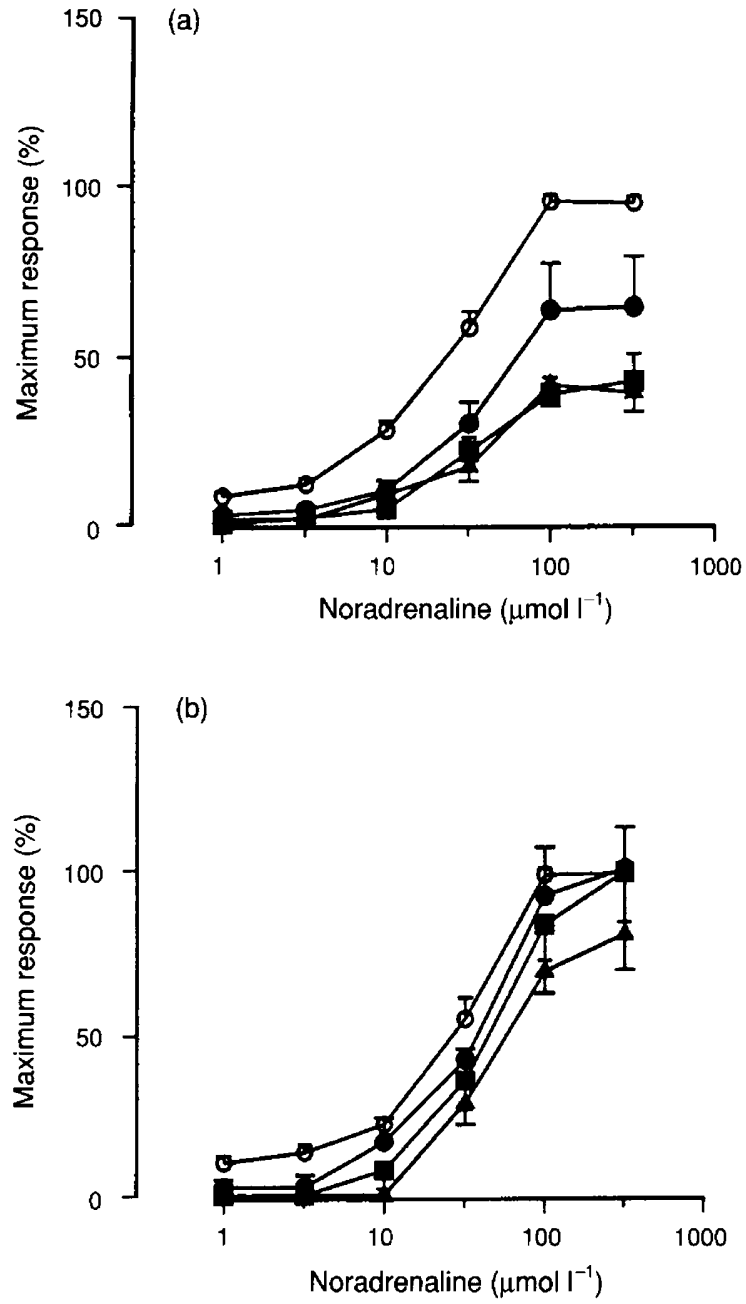

Fig. 1. Effects of pretreatment with phenoxybenzamine on contractions of human vas deferens in response to noradrenaline (applied in the bath for 5-7 min; (a) longitudinal; (b) circular muscle). Doseresponse curves were determined in the absence ( $O$ : controls; $n=5-6$ ) and after pretreatment with phenoxybenzamine applied in the bath for different durations: $0.1 \mu \mathrm{mol} 1^{-1}$ either for $15 \min (-n=6)$ or $25 \min (\Lambda ; n=5-7)$ and $1.0 \mu \mathrm{mol} l^{-1}$ for $15 \min (\boldsymbol{\square} ; n=5-7)$. Tissues were superfused with drug-free Krebs' solution for 35-45 min after the pretreatment. Contractions of the circular compared with the longitudinal muscle were much less sensitive to inhibition by phenoxybenzamine. Data are expressed as a percentage of the maximum response corrected for time-dependent change in tissue sensitivity to noradrenaline. Maximum control responses were $0.74 \pm 0.09 \mathrm{mN}$ ( $n=24$; longitudinal muscle) and $0.31 \pm 0.03 \mathrm{mN}(n=23$; circular muscle). All values represent means \pm SEM.

phenoxybenzamine were applied simultaneously in the bath and via the tissue lumen ( $n=5$, not shown).

These remarkably different effects on the muscle types are also observed clearly in specimens that displayed a combined response of the longitudinal (upward contractions) and circular (downward contractions) muscle to noradrenaline (100 $\mu \mathrm{mol}$ $1^{-1}$; Fig. 3). Prazosin (0.1-10 $\mu \mathrm{mol} \mathrm{l}^{-1}$, applied only in the bath) inhibited and at $1 \mu \mathrm{mol} \mathrm{I}{ }^{-1}$ abolished the contraction of both muscle types. In contrast, phenoxybenzamine (0.1-10 $\mu \mathrm{mol} \mathrm{l}^{-1}$, applied only in the bath) inhibited contractions of the longitudinal muscle but appeared to enhance
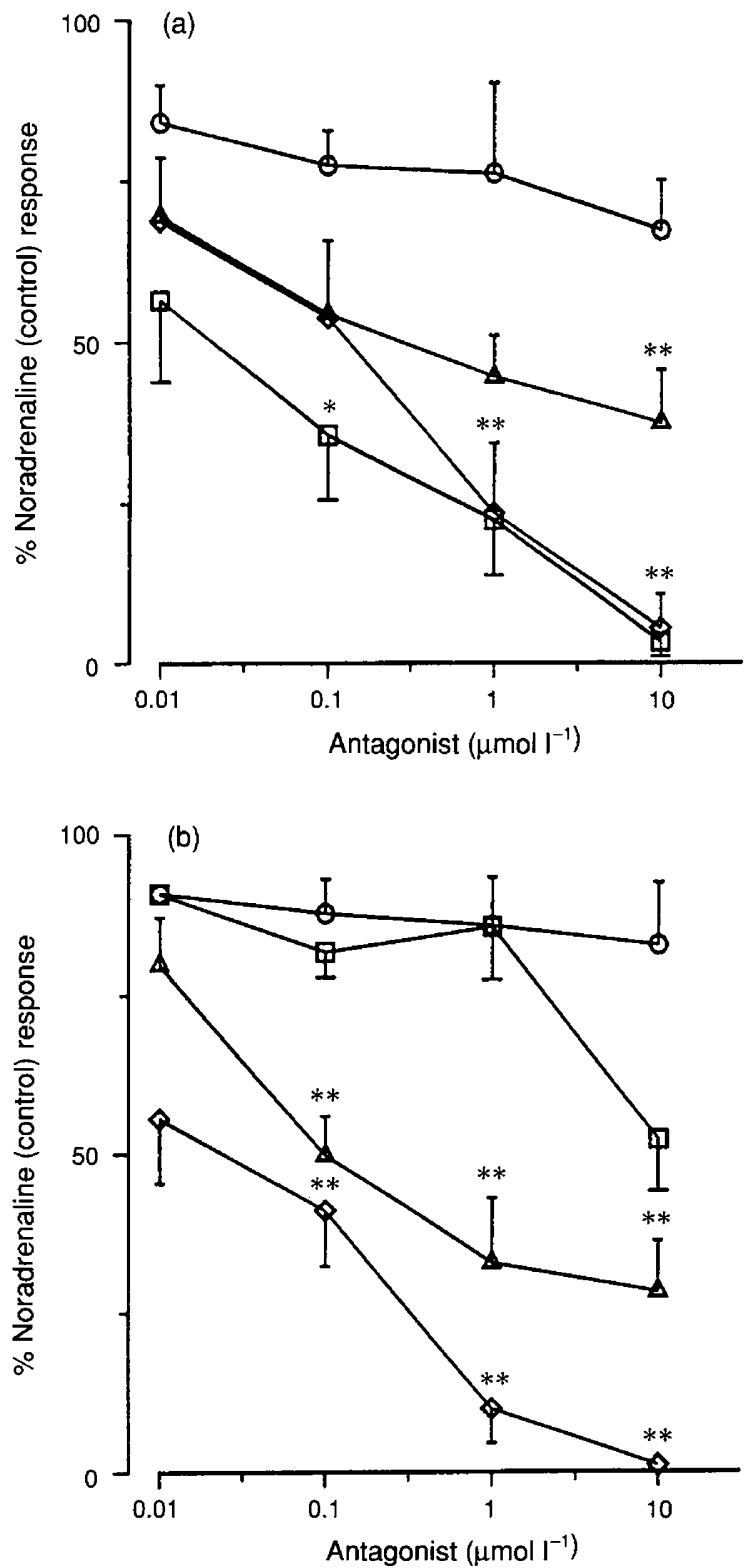

Fig. 2. Comparative effects of graded concentrations of different $\alpha_{1}$-adrenoceptor antagonists on sequential contractions evoked by noradrenaline ( $100 \mu \mathrm{mol} \mathrm{I}^{-1}$; applied for 5-7 min) in (a) longitudinal muscle and (b) circular muscle of human vas deferens. Contractions of both muscle types ( $\bigcirc$; time-matched controls; $n=5-6)$ were inhibited by either prazosin $\left(\diamond ; 0.01-10 \mu \mathrm{mol} \mathrm{l}^{-1} ; n=5\right)$ or benextramine $(\triangle$; $\left.0.01-10 \mu \mathrm{mol} \mathrm{l}^{-1} ; n=4\right)$. In comparison, phenoxybenzamine in the dose range $0.01-1 \mu \mathrm{mol} \mathrm{l}^{-1}(\square ; n=6-7)$ caused the inhibition of the longitudinal but not the circular muscle. The tissues were exposed to each concentration of antagonist for 30-35 min before activation with noradrenaline and contractions expressed as a percentage of the initial drug-free control in the same tissue. The initial response in the sequence measured $0.89 \pm 0.1 \mathrm{mN}(n=21$; longitudinal muscle) and $0.31 \pm 0.05 \mathrm{mN} \quad(n=21$; circular muscle). All values represent means \pm SEM. ${ }^{*} P<0.05 ; * P<0.01$.

contractions of the circular muscle. Presumably inhibition of the longitudinal muscle response allows full expression of the phenoxybenzamine-resistant contraction of the circular muscle. 
(a)

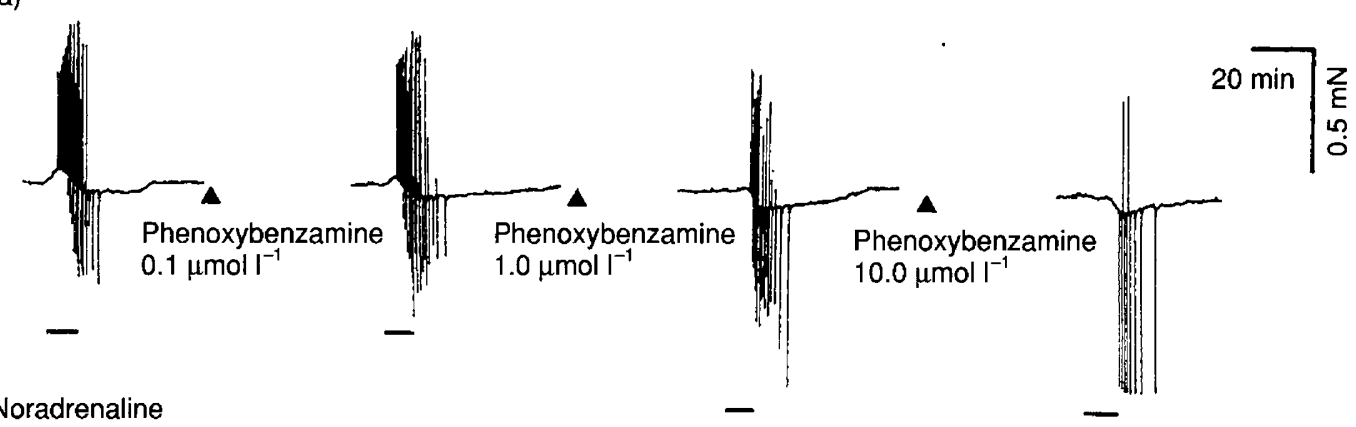

(b)

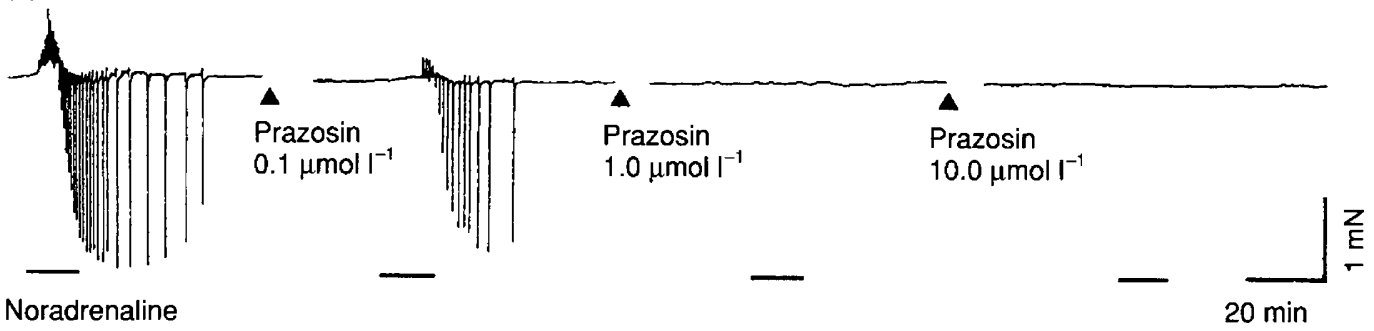

Fig. 3. Typical records showing different effects of (a) phenoxybenzamine and (b) prazosin on the response of specimens that displayed a combination of longitudinal (upward contractions) and circular (downward contractions) muscle responses to noradrenaline ( $100 \mu \mathrm{mol} \mathrm{l}^{-1}$; drugs were added in the bath). Prazosin $\left(0.1-10.0 \mu \mathrm{mol} \mathrm{l} \mathrm{l}^{-1}\right.$ ) inhibited the contractions of both the longitudinal and circular muscle. Phenoxybenzamine $\left(0.1-10.0 \mu \mathrm{mol} \mathrm{l}{ }^{-1}\right)$ differentially inhibited the longitudinal but not the circular muscle. The tissues were exposed to each dose of antagonist for 30-35 min before activation with noradrenaline. Horizontal lines indicate period of drug application. Further preparations with combined responses (phenoxybenzamine, $n=12$; prazosin, $n=6$ ) gave similar results.

\section{Effects of phenoxybenzamine in calcium-free medium}

Noradrenaline activates smooth muscle by mobilizing both extra- and intracellular calcium. Experiments to clarify the effects of phenoxybenzamine on the $\alpha_{1}$-adrenoceptors coupled to these different mechanisms for increasing cytosolic calcium were carried out. Thus, contractions to noradrenaline (100 $\mu \mathrm{mol}^{-1}$ ) were studied during prolonged perfusion in calcium-free media and on restoration of calcium in the presence and absence of phenoxybenzamine.

The withdrawal of calcium from the perfusing medium for 35-40 min inhibited the rhythmic contractions and reduced markedly the sustained (tonic) contraction of the longitudinal and circular muscle to noradrenaline $\left(100 \mu \mathrm{mol} \mathrm{I}^{-1}\right)$.

Phenoxybenzamine $\left(0.1-1 \mu \mathrm{mol} \mathrm{l}^{-1}\right)$ reliably inhibited the calcium-free contractions of longitudinal (Fig. 4a) but not circular muscle (Fig. 4b). Furthermore, reperfusion with normal Krebs' saline (calcium: $2.5 \mathrm{mmol} \mathrm{l}^{-1}$ ) in the continued presence of phenoxybenzamine $\left(1 \mu \mathrm{mol} \mathrm{l}{ }^{-1}\right)$ also produced different effects. Relative to time-matched controls, recovery of the contraction in the circular (Fig. 4b) but not the longitudinal (Fig. 4a) muscle was unchanged when noradrenaline (100 $\mu \mathrm{mol} \mathrm{l^{-1 }}$ ) was applied $55-70 \mathrm{~min}$ and $\geq 90 \mathrm{~min}$ after restoration of extracellular calcium. Thus phenoxybenzamine inhibited contractions of the longitudinal but not the circular muscle to noradrenaline both in the presence or absence of extracellular calcium.

\section{Effects of chloroethylclonidine}

The involvement of chloroethylclonidine-sensitive $\alpha_{1 B^{-}}$ adrenoceptors was examined on responses of the longitudinal and circular muscle. In normal Krebs' saline (calcium: $2.5 \mathrm{mmol}$ $1^{-1}$; Fig. $\left.5 \mathrm{a}\right)$ or calcium-free/EGTA $\left(1 \mathrm{mmol} \mathrm{l}^{-1}\right.$; Fig. $5 \mathrm{~b}, \mathrm{c}$ ) solution, chloroethylclonidine (up to $100 \mu \mathrm{mol} \mathrm{l}^{-1}$ ) produced little change in the response of both muscle types to noradrenaline $\left(100 \mu \mathrm{mol} \mathrm{l}^{-1}\right)$. However, on restoration of calcium for 60-90 min, chloroethylclonidine $\left(100 \mu \mathrm{mol} \mathrm{l}^{-1}\right)$ reliably suppressed the recovery of contraction evoked by noradrenaline $\left(100 \mu \mathrm{mol} \mathrm{l}^{-1}\right)$ in the longitudinal but not the circular muscle (Fig. 5b).

\section{Discussion}

The main finding of this study is that pretreatment with phenoxybenzamine readily inhibited contractions induced by noradrenaline in longitudinal muscle of human vas deferens but that contractions of circular muscle were substantially resistant to the antagonist. Activation of the tissue either via the intramural nerves or by exogenous noradrenaline involves mainly postjunctional $\alpha_{1}$-adrenoceptors (Birmingham, 1968; McLeod et al., 1973; Anton and McGrath, 1977; Hedlund et al., 1985). This is consistent with the finding that responses of both muscle types to noradrenaline were inhibited by prazosin. The 
(a)

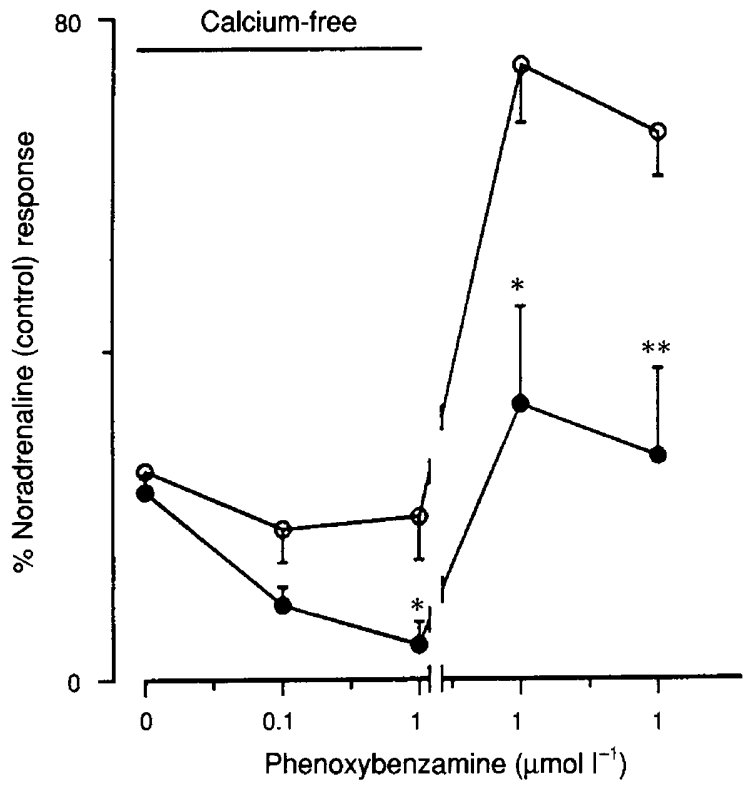

(b)

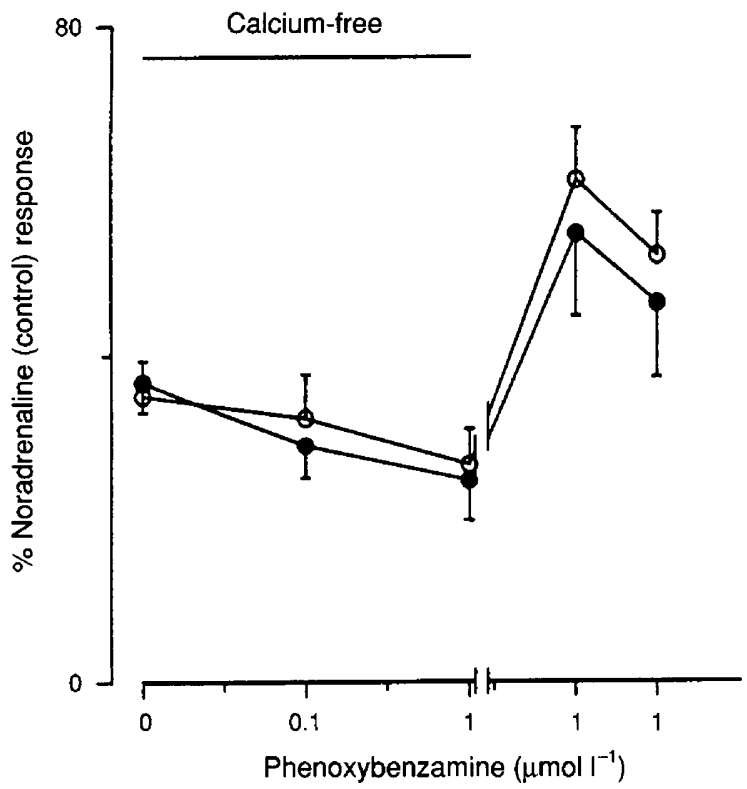

Fig. 4. Effects of phenoxybenzamine on contractions of (a) longitudinal and (b) circular muscle in response to noradrenaline $\left(100 \mu \mathrm{mol} 1^{-1}\right.$, applied in the bath for 7-10 min) during prolonged perfusion in calcium-free medium containing EGTA $\left(1 \mathrm{mmol} \mathrm{I}^{-1}\right)$ and on restoration of extracellular calcium $\left(2.5 \mathrm{mmol}^{-1}\right.$, indicated by breaks on the graphs and abscissa; $(O$ : time-matched controls; $n=6-7)$. Contraction of the longitudinal but not the circular muscle in calcium-free medium was inhibited by phenoxybenzamine $\left(\bullet ; 0.1-1 \mu \mathrm{mol} \mathrm{l}^{-1}\right.$, applied in the bath for $35-40 \mathrm{~min}$ at each concentration, $n=6-7$ ). Continued exposure to phenoxybenzamine $\left(1 \mu \mathrm{mol} \mathrm{l}^{-1}\right)$ during restoration of calcium $\left(2.5 \mathrm{mmol} \mathrm{l} \mathrm{l}^{-1}, 55-70\right.$ and $\left.\geq 90 \mathrm{~min}\right)$ also produced a differential inhibition of the muscle types. Data are expressed as a percentage of control evoked by noradrenaline (100 $\mu \mathrm{mol} \mathrm{l}^{-1}$; longitudinal muscle: $0.51 \pm 0.06 \mathrm{mN}, n=12$ and circular muscle: $0.45 \pm 11 \mathrm{mN}, n=14$ ) before withdrawal of calcium. All values represent means \pm SEM. $* P<0.05 ; * * P<0.01$. relative resistance of circular muscle to phenoxybenzamine could be due to reserve $\alpha_{1}$-adrenoceptors for noradrenaline. However, irreversible inactivation of $\alpha_{1}$-adrenoceptors with benextramine, in comparison with that by phenoxybenzamine, inhibited contractions of both muscle types. Furthermore, a differential inhibition of the muscle types by phenoxybenzamine was also observed in calcium-free solution. In other tissues, contractions evoked in calcium-free media exhibit no receptor reserve for the agonist (Heaslip and Rahwan, 1983; also see Takeyasu et al., 1979; Nichols and Ruffolo, 1988; Suzuki et al., 1990).

Timmermans et al. (1983, 1985) reported that phenoxybenzamine but not benextramine selectively inactivates "... $\alpha_{1}$-adrenoceptor-mediated contractions that are not dependent on the influx of extracellular calcium". Our previous studies showed that the muscle types in the human vas deferens rely to different degrees on different mechanisms for increasing cytosolic calcium. Thus, direct activation by depolarization with high concentrations of extracellular potassium more readily evokes tonic contraction of the circular than it does the longitudinal muscle (Smith and Amobi, 1992; Amobi and Smith, 1993a). Caffeine, an agent that contracts smooth muscle by releasing intraceliular calcium, predominantly activates longitudinal but rarely circular muscle (Amobi and Smith, 1993a, 1995; see also Foveaus et al., 1987). However, noradrenaline contracted both longitudinal and circular muscle in calcium-free media and thus appears able to release intracellular calcium in both muscle types. This contrasts with the effect of caffeine and suggests that $\alpha_{1}$-adrenoceptors in the longitudinal and circular muscle may be coupled to different mechanisms of intracellular calcium release. Initial pharmacological studies (Han et al., 1987) suggested that responses using intracellular and extracellular calcium depended, respectively, on activation of chloroethylclonidine-sensitive and insensitive $\alpha_{1}$ adrenoceptors, putatively identified as $\alpha_{1 \mathrm{~B}^{-}}$and $\alpha_{1 \mathrm{~A}^{-}}$-subtypes. There is now evidence that activation of these subtypes is coupled, via different biochemical pathways, to intracellular calcium release mechanisms (see Wilson and Minneman, 1990).

Furukawa et al. (1994) reported that responses induced in the human vas deferens by phenylephrine were relatively insensitive to chloroethylclonidine. Presumably, most of this response depends on intracellular mechanisms, as the responses are largely resistant to the calcium entry antagonist, nifedipine. Contractions of the rat vas deferens induced by exogenous noradrenaline show a comparable insensitivity to chloroethylclonidine (Martinotti et al., 1991; Mallard et al., 1992; Ohmura et al., 1992; Aboud et al., 1993; Bultmann et al., 1994). We have reported that contractions of the rat vas deferens in response to noradrenaline in the absence of extracellular calcium are inhibited by the $\alpha_{1 \mathrm{~A}}$-adrenoceptor subtype selective antagonist, 5-methylurapidil, but not by chloroethylclonidine (Amobi and Smith, 1994b). In the study reported here, chloroethylclonidine-sensitive $\alpha_{1}$-adrenoceptors appear not to be involved directly in activating calcium influx-dependent or influx-independent contractions of either muscle type. However, chloroethylclonidine effectively blocked the recovery of responses from calcium-free conditions in the longitudinal but not in the circular muscle. The report by Schwietert et al. (1991) that phenoxybenzamine exhibits a much higher affinity (1000fold) for a population of $\alpha_{1}$-adrenoceptors inactivated by 

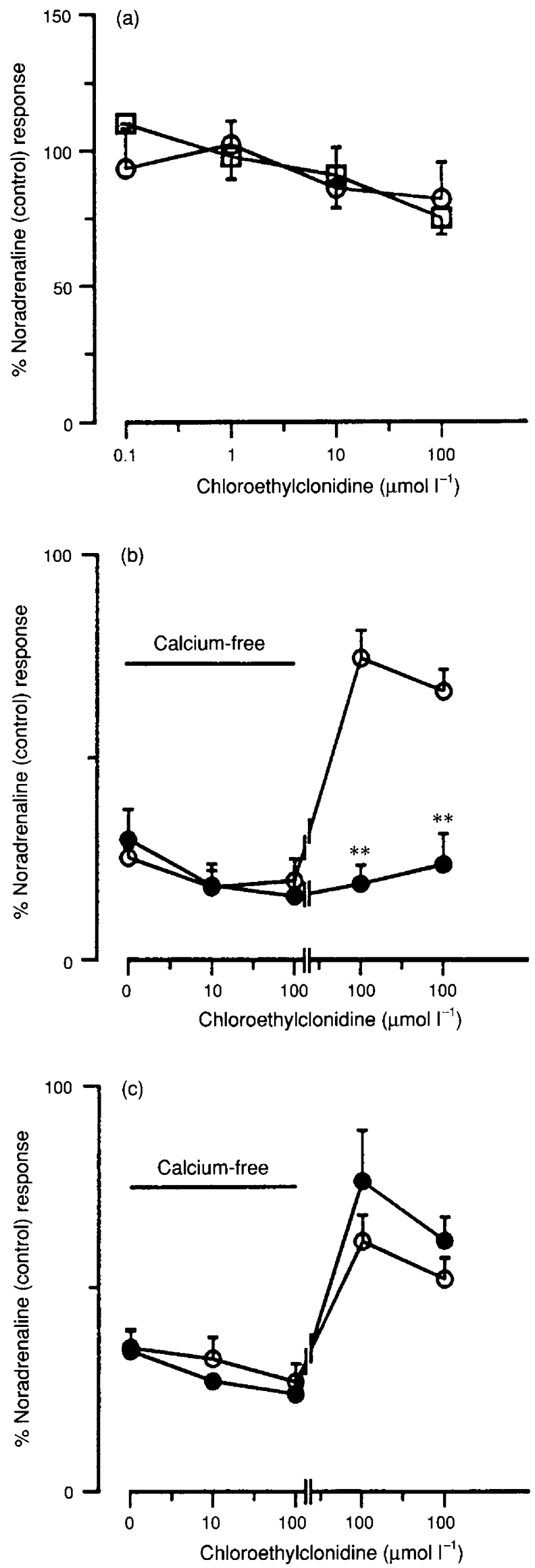

chloroethylclonidine suggests a mechanism for the selectivity of phenoxybenzamine: the longitudinal muscle may depend for much of its response on a calcium store which is replenished via activation of chloroethylclonidine-sensitive $\alpha_{1}$-adrenoceptors. Pretreatment with phenoxybenzamine would therefore selectively block the replenishment of the activator pool of calcium in the longitudinal muscle. Presumably, it would be this same pool that is readily activated directly by caffeine, or by $\alpha_{1}$-selective adrenoceptor agonists, phenylephrine or methoxamine (Amobi and Smith, 1993b, 1995; Furukawa et al., 1994) and is sensitive to ryanodine (Amobi and Smith, 1994c).

Functionally, the co-ordinated contractions of longitudinal and circular muscle during neural excitation provides the propulsive component to sperm transport and ensures sperm emission (Batra, 1974). In relation to the contraceptive action of phenoxybenzamine, the physiological consequences of the differential inhibition of longitudinal but not of circular muscle contraction will be, in vivo, the disruption of the propulsive function of the vas deferens and a constriction of the tissue lumen. This will impede sperm transport by a sphincter-like effect and inhibit sperm emission. The aspermia and absence of retrograde ejaculation reported in men treated with phenoxybenzamine (Homonnai et al., 1984) does suggest an inhibition of the propulsive component of sperm transport. The effects of phenoxybenzamine reported here are comparable to the actions of the neuroleptic, thioridazine, on the responses of the human vas deferens (Amobi and Smith, 1992). Both drugs, in comparison to their pharmacological and therapeutic counterparts, inhibit sperm emission in patients (Greenberg and Carrillo, 1968; Kotin et al., 1976; Kedia and Persky, 1981; Homonnai et al., 1984). The results of this and previous studies (Amobi and Smith, 1992, 1993a, 1993b, 1994a, 1995) indicate that the muscle types of the human vas deferens differ in physiological and pharmacological properties. Such differences may be exploited in the development of drugs either to enhance the contractile activity of a patent but aperistaltic tissue or to block functional propulsion and provide a shortterm, reversible, non-hormonal male contraceptive.

Fig. 5. Effects of chloroethylclonidine on contractions of the longitudinal and circular muscle in response to noradrenaline $(100 \mu \mathrm{mol}$ $1^{-1}$, applied in the bath for 7-10 min). (a) Contractions of the longitudinal $(O ; n=3)$ and circular $(\square ; n=3)$ muscle in the normal Krebs' solution (calcium, $2.5 \mathrm{mmol} \mathrm{1}^{-1}$ ) were unaffected by chloroethylclonidine $\left(0.1-100 \mu \mathrm{mol} \mathrm{l}^{-1}\right.$, applied for $40-45 \mathrm{~min}$ at each concentration). Data are expressed as a percentage of time-matched controls (longitudinal muscle: $0.71 \pm 0.34 \mathrm{mN}, n=6$ and circular muscle: $0.2 \pm 0.05 \mathrm{mN}, n=5$ ). (b,c) Contractions of both muscle types during prolonged perfusion in calcium-free media containing EGTA ( $1 \mathrm{mmol} \mathrm{l}^{-1}$. $\mathrm{O}$ : time-matched controls; $n=6-7$ ) were also unchanged by chloroethylclonidine $\left(10 ; 100 \mu \mathrm{mol} \mathrm{l}^{-1}\right.$ applied for 40-45 $\mathrm{min}$ at each concentration, $n=4$ each). On restoration of extracellular calcium $\left(2.5 \mathrm{mmol} 1^{-1}\right.$ for $40-60$ and $>90 \mathrm{~min}$, indicated by breaks on the graph and abscissa) recovery of longitudinal but not the circular muscle contraction was inhibited by chloroethylclonidine $\left(100 \mu \mathrm{mol} \mathrm{l}^{-1}\right)$. Data are expressed as a percentage of control response evoked by noradrenaline $(100 \mu \mathrm{M}$; longitudinal muscle: $0.55 \pm 0.09 \mathrm{mN}, n=10$ and circular muscle: $0.61 \pm 0.14 \mathrm{mN}$, $n=10$ ) before the withdrawal of calcium. All values represent means \pm SEM. $* * P<0.01$. 
The authors thank J. Pryor, J. A. McEwan and King's College Hospital for vasectomy specimens and King's College Research Strategy Fund for financial support.

\section{References}

Aboud R, Shafii M and Docherty IR (1993) Investigation of the subtype of $\alpha_{1}$-adrenoceptor mediating contraction of the rat aorta, vas deferens and spleen British Journal of Pharmacology 109 80-87

Amobi NIB and Smith ICH (1992) Effects of thioridazine on mechanical responses of the human vas deferens induced by noradrenaline or potassium Journal of Reproduction and Fertility 98 1-10

Amobi NIB and Smith ICH (1993a) The relative importance of extracellular and intracellular calcium in the responses of the human vas deferens to noradrenaline and potassium: a study using $\mathrm{Ca}^{2+}$ deprivation and $\mathrm{Ca}^{2+}$ antagonists Journal of Autonomic Pharmacology 13 177-192

Amobi NIB and Smith ICH (1993b) Differential actions of noradrenaline and $\alpha_{1}$-adrenoceptor agonists on the longitudinal and circular muscle of human vas deferens Journal of Physiology 467 51P

Amobi NIB and Smith ICH (1994a) Contrasting effects of $\alpha_{1}$-adrenoceptor antagonists on the human vas deferens Journal of Physiology $47978 \mathrm{P}$

Amobi NIB and Smith ICH (1994b) Contractions of isolated rat and human vas deferens to exogenous noradrenaline in calcium-free medium; effects of $\alpha_{1 \mathrm{~A}^{-}}$ and $\alpha_{1 \mathrm{~B}}$-adrenoceptor antagonists Journal of Physiology 480 II4P

Amobi NIB and Smith ICH (1994c) Effects of ryanodine on contractions of isolated human vas deferens to noradrenaline and caffeine journal of Physiology 475 52P

Amobi NIB and Smith ICH (1995) The human vas deferens: correlation of response pattern to noradrenaline and histological structure European Journal of Pharmacology 273 25-34

Anton PG and McGrath JC (1977) Further evidence for adrenergic transmission in the human vas deferens Journal of Physiology 273 45-55

Batra SK (1974) Sperm transport through vas deferens: review of hypotheses and suggestion for a quantitative model Fertility and Sterility 25 186-202

Benfy BG (1982) Two long acting $\alpha$-adrenoceptor blocking drugs: benextramine and phenoxybenzamine Trends in Pharmacological Sciences 3470

Birmingham AT (1968) The human vas deferens: its response to electrical stimulation and to drugs Brifish Journal of Pharmacology $34692 \mathrm{P}$

Brock G and Lee T (1993) Drug-induced male sexual dysfunction Drug Safety 8 $414-426$

Bultmann R, Kurz KA and Starke K (1994) $\alpha_{1}$-Adrenoceptors and calcium sources in adrenergic neurogenic contractions of rat vas deferens British Journal of Pharmacology 111 151-158

Fovaeus M, Andersson K-E and Hedlund H (1987) Calcium channel blockade and contractile responses in isolated human vas deferens Journal of Urology 138 $654-658$

Furukawa K, Wass N, McKinney SJ, Chapple CR, Smith D, Rosario DJ, Uchiyama $T$ and Chess-Williams $\mathbf{R}$ (1994) $\alpha_{1}$-Adrenoceptor subtype mediating contractile responses of the human vas deferens British Jounral of Psychiatry 112 $566 \mathrm{P}$

Greenberg HR and Carrillo C (1968) Thioridazine-induced inhibition of masturbatory ejaculation in an adolescent American Journal of Psychiatry 124 991-993

Hamilton CA, Reid JL and Summer DJ (1983) Acute effects of phenoxybenzamine on $a$-adrenoceptor responses in vivo and in vitro: relation of in vitro pressor responses to the number of specific adrenoceptor binding sites Joumal of Cardiovascular Pharmacology 5 868-873

Han C, Abel PW and Minneman K (1987) $\alpha_{1}$-Adrenoceptor subtypes linked to different mechanisms for increasing intracellular $\mathrm{Ca}^{2+}$ in smooth muscle Nature 329 333-335

Heaslip RJ and Rahwan RG (1983) Norepinephrine-induced contractions of the rat aorta in the absence of extracellular calcium I. Effects of $\alpha$-adrenoceptor blockers General Pharmacology 14 497-503
Hedlund H, Andersson K-E and Larsson B (1985) Effect of drugs interacting with adrenoceptors and muscarinic receptors in the epididymal and prostatic parts of the human isolated vas deferens Journal of Autonomic Pharmacology 5 261-270

Homonnai ZT, Shilon M and Paz GF (1984) Phenoxybenzamine: an effective male contraceptive pill Contraception 29 479-489

Kedia KR and Persky L (1981) Effect of phenoxybenzamine (Dibenzyline) on sexual function in man Urology 18 620-622

Kotin J, Wilbert DE, Verburg D and Soldinger SM (1976) Thioridazine and sexual dysfunction American Journal of Psychiatry 133 82-85

McLeod DG, Reynolds DG and Demaree GE (1973) Some pharmacological characteristics of the human vas deferens Investigative Urology 10 338-341

Mallard NJ, Marshall RW, Sithers AJ and Spriggs TLB (1992) Separation of putative $\alpha_{1 \mathrm{~A}^{-}}$and $\alpha_{1 \mathrm{~B}^{-}}$adrenoceptor mediated components in the tension response of the rat vas deferens to electrical field stimulation British Journal of Pharmacology 105 727-731

Martinotti E, Breschi MC, Nieri P and Omini C (1991) Differences in activity between noradrenaline and other $\alpha$-agonists in rat vas deferens fournal of Autonomic Pharmacology 11 147-153

Minneman KP (1983) Phenoxybenzamine is more potent in inactivating $\alpha_{1}$ than $\alpha_{2}$-adrenergic receptor binding sites European Journal of Pharmacology 94 I71-174

Nichols AJ and Ruffolo RR (1988) The relationship of $\alpha$-adrenoceptor reserve and agonist intrinsic efficacy to calcium utilization in the vasculature Trends in Pharmacological Sciences 9 236-241

Ohmura T, Oshita M, Kigoshi S and Muramatsu K (1992) Identification of $\alpha_{1}$-adrenoceptor subtypes in the rat vas deferens: binding and functional studies British Journal of Pharmacology 107 697-704

Schwietart HR, Gouw MAM, Wilhelm D, Wilffert B and van Zwieten PA (1991) The role of $\alpha_{\mathrm{I}}$-adrenoceptor subtypes in the phasic and tonic responses to phenylephrine in the longitudinal smooth muscle of the rat portal vein Naunyn Schmiedebergs Archives of Pharmacology 343 463-471

Smith CG and Harclerode JE (1985) Therapeutic drug effects on male reproductive function. In Advances in Reproductive Health Care: Male Fertility and its Regulation pp 39-48 Eds TJ Lobl and ESE Hafez. MTP Press, Lancaster

Smith ICH and Amobi NIB (1992) Calcium stores in longitudinal and circular muscle of isolated human vas deferens Journal of Physiology 45926P

Smith ICH and Bray M (1990) Direct and indirect contractile responses of the human vas deferens and actions of noradrenaline and of calcium antagonists Experimental Physiology 75 33-43

Suzuki E, Tsujimoto T, Tamura K and Hashimoto K (1990) Two pharmacologically distinct $\alpha_{1}$-adrenoceptor subtypes in the contraction of rabbit aorta: each subtype couples with a different $\mathrm{Ca}^{2+}$ signalling mechanism and plays a different physiological role Molecular Pharmacology 38 725-736

Takeyasu K, Uchida S, Wada A, Maruno M, Lai RT, Hata F and Yoshida H (1979) Experimental evidence and dynamic aspects of spare receptor Life Sciences $\mathbf{2 5}$ $1761-1772$

Timmermans PBMWM, Mathy MJ, Korstanje C, Thoolen MJMC, Wilffert B, de Jonge A and van Zwieten PA (1983) Phenoxybenzamine identifies calcium influx dependent and independent mechanisms of vasoconstriction in vivo to cirazoline Naunyn Schmiedebergs Archives of Pharmacology 324 Supplement R54

Timmermans PBMWM, Thoolen MJMC, Mathy MJ, Wilffert B, de Jonge A and van Zwieten PA (1985) Effects of the irreversible $\alpha$-adrenoceptor antagonists phenoxybenzamine and benextramine on the effectiveness of nifedipine in inhibiting $\alpha_{1}$-and $\alpha_{2}$-adrenoceptor mediated vasoconstriction in pithed rats Naunyn Schmiedebergs Archives of Pharmacology $329404-413$

van Zwieten PA (1990) a-adrenoceptor antagonists. In Pharmacology of Antihypertensive Therapeutics pp 105-129 Eds D Ganten and PJ Mulrow. Springer-Verlag, Berlin

Wilson KM and Minneman KP (1990) Different pathways of $\left.{ }_{1}^{[3} \mathrm{H}\right]$ inositol phosphate formation mediated by $\alpha_{\mathrm{Ia}^{-}}$and $\alpha_{1 \mathrm{~b}}$-adrenergic receptors Journal of Biological Chemistry $26517601-17606$ 